\title{
Understanding the Effects of Various Factors on the Public Response to Congestion Charge: A Latent Class Modeling Approach
}

\author{
Sugiarto Sugiarto ${ }^{*}$, Tomio Miwa ${ }^{2}$, Hitomi Sato ${ }^{3}$, Takayuki Morikawa ${ }^{3}$ \\ ${ }^{1}$ Department of Civil Engineering, Syiah Kuala University, Darussalam, Banda Aceh, Indonesia \\ ${ }^{2}$ EcoTopia Science Institute, Nagoya University, Nagoya, Japan \\ ${ }^{3}$ Institute of Innovation for Future Society, Nagoya University, Nagoya, Japan \\ Email: sugiarto@unsyiah.ac.id, miwa@nagoya-u.jp, sato@trans.civil.nagoya-u.ac.jp, morikawa@nagoya-u.jp
}

Received 29 January 2015; accepted 27 March 2015; published 31 March 2015

Copyright (C) 2015 by authors and Scientific Research Publishing Inc.

This work is licensed under the Creative Commons Attribution International License (CC BY).

http://creativecommons.org/licenses/by/4.0/

(c) (i) Open Access

\section{Abstract}

The standard ordered response model (SORM) is a common disaggregate approach with ordered outcomes in which the effects of various exogenous attributes are assumed constant across ordinal choices. In this study, an innovative latent class based generalized ordered response model (LC-GORM) is formulated and used to assess the effects of various factors on respondents' choice behavior with respect to congestion charge proposal for Jakarta, Indonesia. The proposed model probabilistically assigns respondents into selfish and altruistic class memberships (latently) based on their knowledge of the proposed scheme and their specific attributes. Aiming to capture observable preference heterogeneity across ordinal choices and allow the thresholds to be varied across observations, we parameterize the thresholds as a linear function of the exogenous variables for each ordinal preference. Using stated preference data collected in Jakarta in December 2013, we incorporate the influence of a comprehensive set of explanatory variables into four categories: charges, latent variables related to respondent's psychological motivations, mobility attributes and socio-demographic characteristics. Empirical results obviously verify the existence of preference heterogeneity across outcomes. The findings confirm that the altruistic class are more sensitive with respect to acceptance of the scheme, while the selfish class are more sensitive with respect to rejection. The key factors influencing public acceptability include the charge level and respondent variables such as car dependency, awareness of the problem of cars in society, frequency of visits to the city center and frequency of private mode usage.

\section{Keywords}

Respondent's Choice Behavior, Latent Types of Respondents, Latent Class, Congestion Charge

\footnotetext{
${ }^{*}$ Corresponding author.
}

How to cite this paper: Sugiarto, S., Miwa, T., Sato, H. and Morikawa, T. (2015) Understanding the Effects of Various Factors on the Public Response to Congestion Charge: A Latent Class Modeling Approach. Journal of Transportation Technologies, 5, 76-87. http://dx.doi.org/10.4236/jtts.2015.52008 


\section{Introduction}

Traffic gridlock is emerging as a serious hindrance to economic development in many urbanized areas, including Jakarta (the capital of Indonesia). The Jakarta region accounts for $19 \%$ of Indonesia's gross domestic product, amounting to approximately US\$ 118.7 billion [1]. The population of Jakarta accounts for $10 \%$ of the nation's total, and has increased 1.6 times in 20 years-from 17 million in 1990 to 28 million in 2010 [2]. Commuting trips from peripheral areas into Jakarta have grown roughly 1.5 times between 2002 and 2010 [2]. Moreover, the city relies heavily on road transportation, with private vehicles taking a mode share of almost $80 \%$ of trips. The Jakarta police authority reported 7.5 million registered motorcycles and 2.1 million passenger cars, respectively, in 2010. This represents an increase of $464 \%$ (motorcycles) and $201 \%$ (cars) compared to the base year (2000). This tremendous number of motor vehicles results in huge economic losses arising from worsening traffic congestion. Estimates for 2002 suggest that US\$300 million was lost in wasted vehicle operation costs and US\$250 million in travel time [3]. Additionally, a number of externalities are manifested by motorized traffic, including excessive travel times, air pollution and energy consumption. Such externalities have affected Jakarta particularly badly in recently, and have led Jakarta's government to take great interest in how to moderate the problems.

A promising policy measure for the government to mitigate congestion in Jakarta is the adoption of a congestion charge (CC). The term of CC, which is also referred to as road pricing, can be defined as any form of charging for the use of certain roads during times of peak demand [4]. The government of Jakarta desires to replace the existing 3-in-1 High Occupancy Vehicle (HOV) policy, which has had insufficient effect in alleviating traffic congestion, with a CC scheme [2]. A CC policy is regarded as the most effective measure to combat traffic congestion within a city center. Successfully implementations in Singapore, London and Stockholm have effectively mitigated congestion [5]-[7]. Although such schemes are capable of reducing congestion, they are at the same time uniquely difficult to implement [8]. A few cities have attempted such schemes. Rather than technical matters, it is social and legal issues, related to public and political acceptability, that are the major obstacles to implementation [9]. It is argued that most countries with democratic political systems find it hard to implement such schemes. This is confirmed by the experience of several cities that have dropped schemes for lack of public support, such as a proposal in Edinburgh [10] and one in New York City [11]. Understanding this is crucial to any investigation of what might improve public support for such schemes. Support might be affected by whether individuals gain benefits from the scheme or, conversely, find their private mobility affected.

In particular at behavioral research, there are concepts of interest related to psychological indicators. Extensive psychological studies have been carried out to identify individual factors that affect public support, indicating that the acceptability of transport pricing appears to be explained by a wide range of psychological motivations. Public approval strongly correspond to individual perceptions of the policy, such as perceived environmental benefits, improved freedom of movement and knowledge of the charging [12]-[14]. In respect to the CC proposal in Jakarta, a preliminary study on public acceptance was carried out by [15]. Psychometric data obtained from stated preference experiment were used to assess the influence of public consciousness on the acceptability of CC policy. They found that psychological factors such as recognition, fairness, awareness to congestion problem and inhibition of freedom of movement have the most significant influence on determining public approval.

In regards to modeling approach, it is unsurprising that the most commonly applied econometric to evaluate public response behavior is the ordered response model. The SORM imposes a restrictive and monatomic impact to the exogenous attributes of each outcome alternative. Therefore, this study is an attempt to assess the effects of various factors on public choice behavior with respect to the CC proposal in Jakarta by formulating an innovative framework of the LC-GORM. The proposed model probabilistically assigns respondents to selfish and altruistic class member-ships (latently) based on their knowledge on the proposed scheme and their specific attributes.

The rest of this paper is structured as follows. The next section describes the data set, the modeling framework and model estimation. Finally, the conclusions of the study are presented at the end of the paper.

\section{Data}

\subsection{Stated Preference Survey}

This study focused on the city center of Jakarta, as shown in Figure 1. The target zone is CBD, which is a dense 
mix of business and commercial areas. The charging zone is within the CBD, which is also the area proposed for TDM measures by the government of Jakarta [2] [3]. The CBD attracts many visitors and is served by urban arterial roads that experience serious congestion because of most visitors rely on private automobiles.

The stated preference or opinion survey method was used to design questionnaires. The questionnaires were designed to capture relevant information from respondents (visitors to the CBD), such as visitor mobility characteristics, approval of the proposed CC scheme, expectation of changes in mobility habits and socio-demographic attributes (see Table 1). Respondents were asked to answer a set of questions regarding the CC proposal, designed to capture their intentions with respect to such a scheme. This set of questions was related to the individual's psychological motivations corresponding to several indexes as summarize in Table 1. Furthermore, the survey was conducted in November 2013 in the city center of Jakarta. Target respondents were visitors, including commuters, shoppers, commercial visitors and employees of business establishments. A total of 2100 questionnaires were distributed randomly. A total 1641 samples were valid and utilized in this study.

\subsection{Data Profiles}

Figure 2 shows the socio-demographic characteristics of the respondents. It is noteworthy that young people

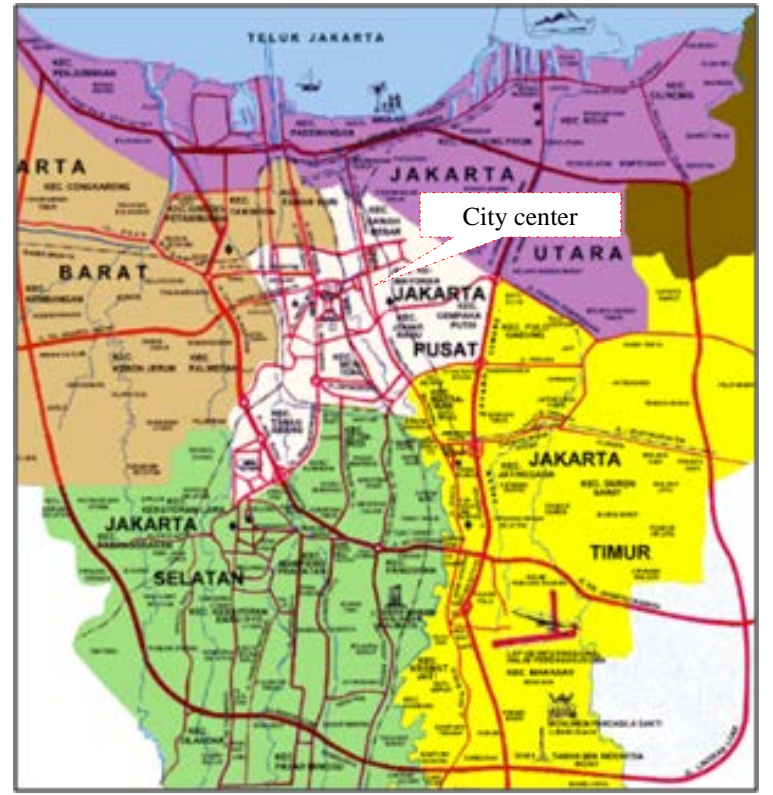

(a)

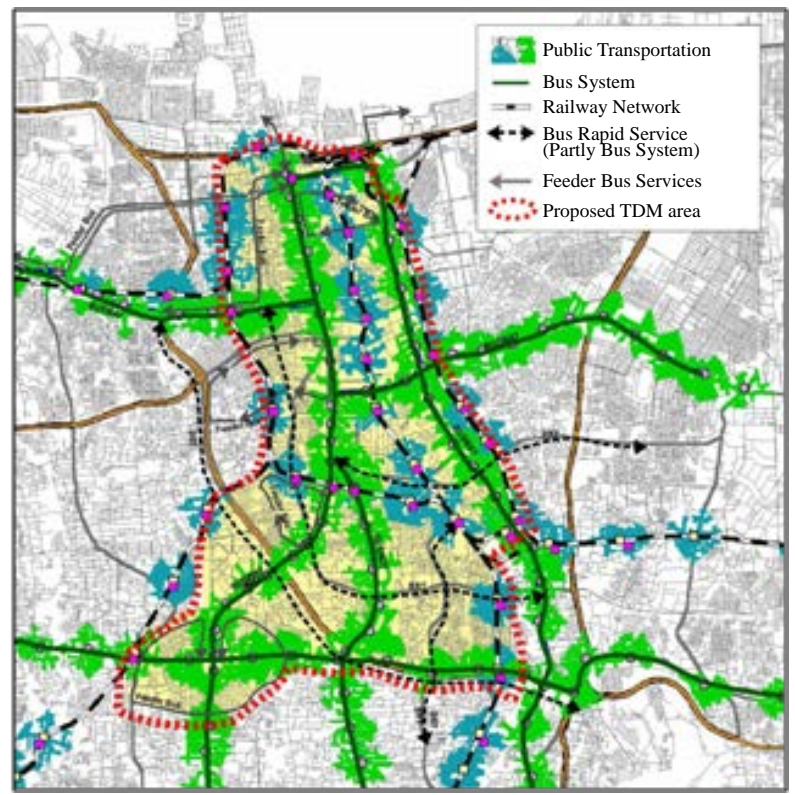

(b)

Figure 1. Study area and the area proposed for charging zone. (a) Jakarta Region; (b) the CC zone.

Table 1. Summary of questions in stated preference questionnaire.

\begin{tabular}{|c|c|c|}
\hline No & Category & Description \\
\hline 1 & Visitor mobility characteristics & $\begin{array}{l}\text { Purpose of trip, number of accompanying persons, and mode choices } \\
\text { Recognition, acceptability, and fairness of CC Inhibition of freedom }\end{array}$ \\
\hline 2 & $\begin{array}{l}\text { General opinion of CC, traffic congestion and the } \\
\text { environment. Respondents were asked to choose } \\
\text { a response from a 4-point Likert scale to road pricing } \\
\text { (i.e. } 1 \text {. well accepted; } 2 \text {. accepted; } 3 \text {. not accepted; } \\
\text { 4. not accepted at all) }\end{array}$ & $\begin{array}{l}\text { Consequences of CC implementation } \\
\text { Opinion on present level of urban transit services } \\
\text { Opinion on city center transport and environment } \\
\text { Extent of recognition of environmental issues } \\
\text { Opinion on government policies and opinion on CC policy }\end{array}$ \\
\hline 3 & $\begin{array}{l}\text { Respondent's mobility responses to } \\
\text { introduction of road pricing }\end{array}$ & $\begin{array}{l}\text { Thoughts about possible different visit behavior on day of } \\
\text { survey under different charging schemes }\end{array}$ \\
\hline 4 & Individual socio-demographics & Gender, age, driver’s license, employment status, annual income \\
\hline 5 & Mobility attributes & $\begin{array}{l}\text { Trip purpose and frequency, mode used, frequency of private } \\
\text { mode usage, frequency of transit service usage }\end{array}$ \\
\hline
\end{tabular}


( $\geq 30$ years) dominate the sample set, accounting for more than $60 \%$ of respondents. The gender distribution is slightly skewed toward males. As regards employment status, the data set indicates that $69 \%$ are employed, with less than $6 \%$ of the sample being housewives or unemployed. Commuters dominate the samples, with nearly $95 \%$ of them making mandatory trips to the CBD (workers/students). Notably, closely three-quarters of the sample have a low annual income. That is, about $73.4 \%$ of the respondents have an annual income below 12 million IDR. A household with an annual income below 22 million IDR is classified as a low income [1].

Figure 3 describes respondents' mobility attributes. The data reveal that close to $70 \%$ of trip makers are licensed drivers. However, this does not mean that $70 \%$ of trip makers used private modes to enter the CBD. It can be seen that the travel mode distribution is slightly skewed toward private modes. That is, $50.4 \%$ of respondents used private modes to visit the CBD. Turning to the purpose of the CBD visit, work and going to school are predominant, accounting for about $59.5 \%$ of the sample. Similarly, $63 \%$ of respondents visit the CBD quite often (3 - 5 days/week or more), with a possible reason for this being that nearly $60 \%$ of trip makers are commuters (working or studying). As expected, the data reveal that approximately $55.7 \%$ of respondents frequently use car ( 3 - 5 days/week or more). In contrast, $33.5 \%$ of respondents quite infrequently use car (up to 3 days/

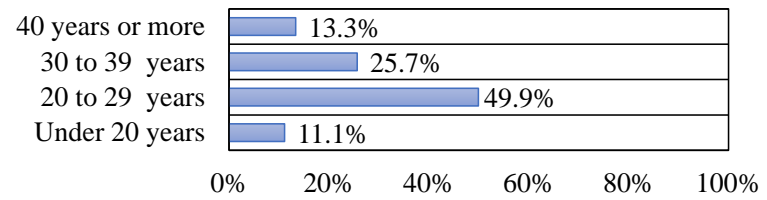

(a)

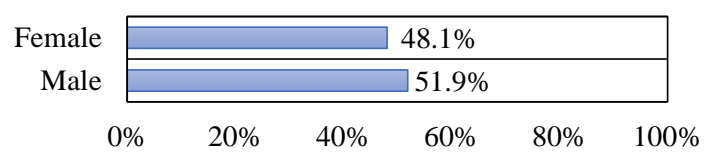

(b)

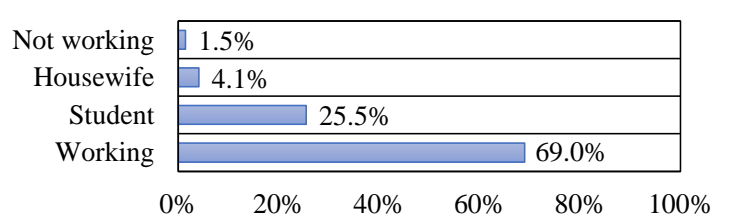

(c)

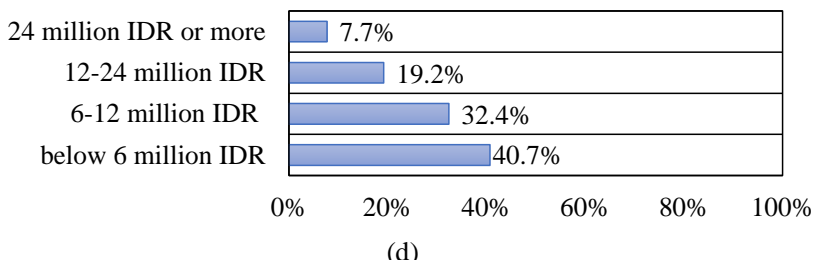

(d)

Figure 2. Respondent's demographic distributions. (a) age; (b) gender; (c) employment status; (d) annual income (1 Indonesian Rupiah/IDR $\cong 12,000$ USD).

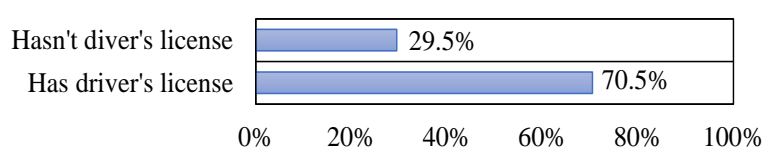

(a)

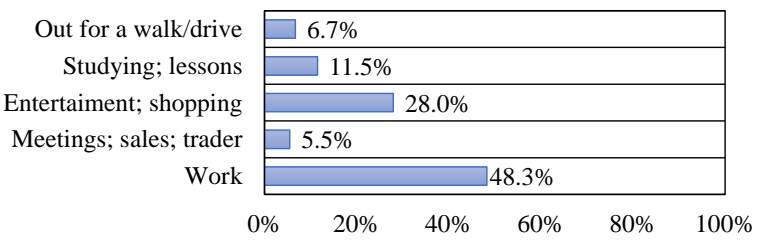

(c)

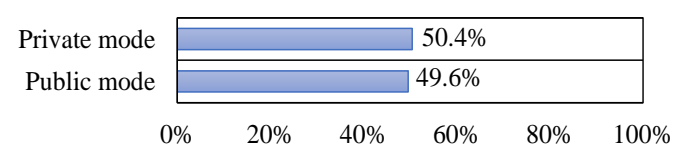

(b)

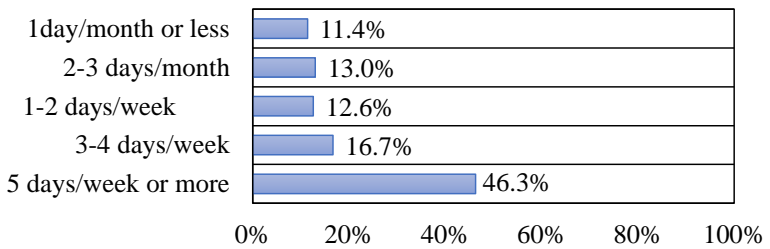

(d)

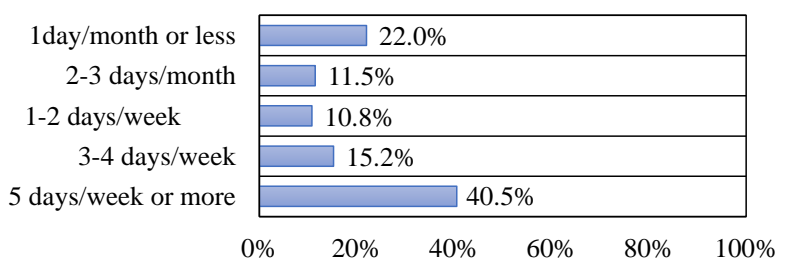

(e)

Figure 3. Respondent's mobility attributes. (a) driver's license; (b) mode used; (c) purpose of visiting CBD; (d) frequency of visiting CBD; (e) frequency of using car. 
month). It seems that respondents prefer to use their own mode because there is only one pleasant means of transit serving the corridors, the Jakarta BRT.

\section{Methodology}

\subsection{Latent Variable Model}

Prior to the latent class ordered response procedure, we estimate latent variables from psychometric data that we obtained from stated preference experiments. The approach used is a common one: confirmatory factor analysis with covariates, formerly known as the multiple-indicators multiple-causes (MIMIC) model, by [16]. Systematically, the MIMIC model consists of a structural equation model and measurement model given by:

$$
\eta_{t}=\mathrm{B} \eta_{t}+\Gamma x_{t}+\zeta_{t} \text { and } y_{t}=\Lambda \eta_{t}+\varepsilon_{t}
$$

where $y_{t}$ is a vector of observable indicator variables, $x_{t}$ is a vector of the exogenous variables that cause $\eta_{t}$, and $\mathrm{B}, \Gamma$ and $\Lambda$ are matrices of factor loading to be estimated. The terms $\zeta_{t}$ and $\varepsilon_{t}$ are measurement errors. In this study parameters were estimated using LISREL 9.1 .

\subsection{Latent Class Ordered Response Model}

\subsubsection{Upper Level Model: Class Membership Selection}

The modeling concept is based on the assumption that there may be discrete classes of decision makers that are not immediately identifiable from the data set (that is, they are latently identified). A CC policy may stimulate a feeling of infringement. That is, a people might psychologically perceive that their freedom will be limited to some extent, leading to negative feelings on becoming conscious of the policy. This represents a feeling of unfairness perceived by "selfish respondents". In contrast, certain people might experience positive feelings on becoming conscious. This reflects a feeling of fairness as experienced by "altruistic respondents". Suppose that the population of respondents consist of $c^{*}$ different behavioral classes: the selfish class (" $s$ ") and the altruistic class (" $a$ "). Respondents in the same class use the same behavior in making their choices. Then, the utility function for individual $i$ belonging to class sand the probability of respondent $i$ belonging to the class membership $s$ or $a$ are respectively given by:

$$
\begin{gathered}
U_{i \mid c=s}=\alpha z_{i}^{\prime}+u_{i} \\
P_{r}\left(c=s \mid z_{i}\right)=\Phi\left(\alpha z_{i}^{\prime}\right) \text { and } P_{r}\left(c=a \mid z_{i}\right)=1-P_{r}\left(c=s \mid z_{i}\right)=1-\Phi\left(\alpha z_{i}^{\prime}\right)
\end{gathered}
$$

where $z_{i}$ is a vector of the respondent's characteristics, $\alpha$ is a vector of the unknown parameters, and $u_{i}$ is class-specific idiosyncratic random disturbance term assumed to be IID standard normal distribution.

\subsubsection{Lower Level Model: Class Specific (Conditional) Choice}

The latent class ordered response model here stated that a conditional on being in class $s$ or $a$, are then simultaneously assigns to the class specific (conditional) choices. A common disaggregate approach with ordering outcomes is the SORM. Let $i(i=1,2, \cdots, I)$ be an index representing the observation unit and let $j(j=1,2, \cdots, J)$ be an index representing the ordinal value $j$ of an ordered-response variable, then the system equation of SORM is written as:

$$
y_{i}^{*}=\beta x_{i}^{\prime}+\varepsilon_{i}, y_{i}=j \text { if } \mu_{j-1}<y_{i}^{*} \leq \mu_{j}
$$

where $x_{i}$ is a vector of the exogenous variables, $\beta$ is a vector of the unknown parameters, representing the individual observations. The random error $\varepsilon_{i}$ is assumed to be IID standard normal distribution. Then, the individual contribution to the unconditional probability can be drawn as:

$$
P_{r}(y=j)=\Phi\left(\mu_{j}-\beta x_{i}^{\prime}\right)-\Phi\left(\mu_{j-1}-\beta x_{i}^{\prime}\right)
$$

where $\Phi($.$) represents a standard normal cumulative density function, and \mu j$ and $\mu j+1$ represents upper and lower thresholds for outcome $j$. Hence, the SORM imposes a restrictive and monatomic impact of the exogenous attributes of each alternatives [17] [18]. To maintain the ordering conditions and allow the thresholds to vary 
across ordinal outcomes, we parametrize the thresholds to be linear function of the covariates [19], with it turn to generalized ordered response model (GORM):

$$
\mu_{j}=\tilde{\mu}_{j}+x^{\prime} \gamma_{j}, j=1, \cdots, J
$$

Substitution of Equation (6) in Equation (5) yields:

$$
P_{r}(y=j)=\Phi\left(\tilde{\mu}_{j}-\beta_{j} x_{i}^{\prime}\right)-\Phi\left(\tilde{\mu}_{j-1}-\beta_{j-1} x_{i}^{\prime}\right)
$$

where $\beta_{j}=\beta-\gamma_{j}$ since $\beta$ and $\gamma_{j}$ can not be identified separately, and it is understood that $\tilde{\mu}_{0}=-\infty$ and $\tilde{\mu}_{j}$ $=\infty$ such that $\Phi(-\infty)=0$ and $\Phi(\infty)=1$. Given above specification, the overall conditional probability of choice preferences $j$ is the sum of those from the two respectively class memberships. Combining Equation (3) and Equation (5) final choice probabilities for latent class based on the SORM (LC-SORM), yields:

$$
\begin{aligned}
P_{r}\left(y_{i}=j \mid z_{i}, x_{i}\right) & =P_{r}\left(c=s \mid z_{i}\right) P_{r}\left(y_{i}=j \mid x_{i}, c=s\right)+\left(1-P_{r}\left(c=s \mid z_{i}\right)\right) P_{r}\left(y_{i}=j \mid x_{i}, c=a\right) \\
& =\Phi\left(\alpha z_{i}^{\prime}\right)\left\{\Phi\left(\mu_{s, j}-\beta_{s} x_{i}^{\prime}\right)-\Phi\left(\mu_{s, j-1}-\beta_{s} x_{i}^{\prime}\right)\right\} \\
& +\left(1-\Phi\left(\alpha z_{i}^{\prime}\right)\right)\left\{\Phi\left(\mu_{a, j}-\beta_{a} x_{i}^{\prime}\right)-\Phi\left(\mu_{a, j-1}-\beta_{a} x_{i}^{\prime}\right)\right\}
\end{aligned}
$$

and compounding Equation (3) and Equation (7) turns to final choice probabilities for the LC-GORM:

$$
\begin{aligned}
P_{r}\left(y_{i}=j \mid z_{i}, x_{i}\right)= & P_{r}\left(c=s \mid z_{i}\right) P_{r}\left(y_{i}=j \mid x_{i}, c=s\right)+\left(1-P_{r}\left(c=s \mid z_{i}\right)\right) P_{r}\left(y_{i}=j \mid x_{i}, c=a\right) \\
& =\Phi\left(\alpha z_{i}^{\prime}\right)\left\{\Phi\left(\tilde{\mu}_{s, j}-\beta_{s, j} x_{i}^{\prime}\right)-\Phi\left(\tilde{\mu}_{s, j-1}-\beta_{s, j-1} x_{i}^{\prime}\right\}\right. \\
& +\left(1-\Phi\left(\alpha z_{i}^{\prime}\right)\right)\left\{\Phi\left(\tilde{\mu}_{a, j}-\beta_{a, j} x_{i}^{\prime}\right)-\Phi\left(\tilde{\mu}_{a, j-1}-\beta_{a, j-1} x_{i}^{\prime}\right\}\right.
\end{aligned}
$$

Eventually, the likelihood function for the entire observations can be written as:

$$
L\left(\gamma, \beta, \tilde{\mu}_{s, j}, \cdots, \tilde{\mu}_{s, j-1}, \tilde{\mu}_{a, j}, \cdots, \tilde{\mu}_{a, j-1} ; z, y, x\right)=\prod_{i=1}^{I} \prod_{j=1}^{J}\left[P_{r}\left(y_{i}=j \mid z_{i}, x_{i}\right)^{h_{i j}}\right]
$$

where $h_{i j}$ is the indicator function, 1 if a respondent $i$ chooses outcome $j, 0$ otherwise. $P r_{i j \mid c}$ are the choice probabilities of a respondent $i$ being in choice outcome $j$ conditional on class membership $c$. In this study, the log likelihood function is written and implemented in GAUSS econometric programming version 3.2.32.

\section{Analysis}

\subsection{Estimation Results of Latent Variable}

The ordinal psychological-related questions included in the stated preference experiments transform into latent variables representing constructs of psychological indicators using a 4-point Likert scale. Variables notation, definition and empirical setting for both indicators and causes are summarized in Table 2 and Table 3.

Table 2 and Table 3 give the estimation results of the MIMIC model. The factors loading for indicators and causes into latent variables are listed in Table 2 and Table 3, respectively. A number of indices were computed to explain the fit of the model in the model fitting process. The fit indicators include the comparative fit index $(\mathrm{CFI}=0.92)$, the root mean square error of approximation (RMSEA $=0.09)$ and the standardized root mean square residual $(S R M R=0.07)$ likewise exhibit moderate acceptable fits [20].

Table 2 displays that the validity of CC adoption (APR, REC and APC) have similarly a positive tendency of contribution for scheme proposal. Concerning to CDC, it appears that transit and its availability have negative scores for the CDC. A negative sign of transit availability may partially indicator of the car dependency in Jakarta. Interestingly, IFM contributes as barrier for correct and acceptable scheme while doubts about the ability of CC policy in mitigate congestion has a positive sign.

Concerning to respondent's socio-demographic attributes, Table 3 displays the gender variable of males have a positive marks the latent variables of car dependency (CDC) and inhibition freedom of movement (IFM). It seems that male respondents are more dependent on private car use. Consequently they will perceive CC 
Table 2. Description, empirical setting and factor loading for indicators (measured equation).

\begin{tabular}{|c|c|c|c|c|c|}
\hline \multicolumn{4}{|c|}{ Variables } & \multicolumn{2}{|c|}{ Path coefficients } \\
\hline \multicolumn{2}{|r|}{ Latent } & \multicolumn{2}{|r|}{ Indicator ${ }^{*}$} & Coefficient & t-statistic \\
\hline \multirow{3}{*}{ APR } & \multirow{3}{*}{ Appropriateness of CC adoption } & CRP & CC is correct policy & 1.000 & - \\
\hline & & ACP & CC will be accepted by the public & 0.893 & 39.32 \\
\hline & & FRP & CC is a fair policy & 0.878 & 38.13 \\
\hline \multirow{4}{*}{ REC } & \multirow{4}{*}{ Recognition of scheme's effects } & ICG & CC implementation to improve congestion & 1.000 & - \\
\hline & & IGW & CC implementation to mitigate global warming & 0.996 & 56.47 \\
\hline & & MCG & CC will be able to mitigate congestion & 0.866 & 42.13 \\
\hline & & MEP & CC will be able to to mitigate environmental problem & 0.852 & 40.95 \\
\hline \multirow{3}{*}{ CDC } & \multirow{3}{*}{ Car dependency } & CNL & A car is absolutely necessary in daily life & 1.000 & - \\
\hline & & PNL & Public mode is necessary in daily life & 0.783 & 7.14 \\
\hline & & PAV & Public mode is easy and convenient to use & -1.072 & -8.59 \\
\hline \multirow{2}{*}{ APC } & \multirow{2}{*}{ Awareness of car society } & TGC & Traffic is congested in the CBD & 1.000 & - \\
\hline & & PED & The pedestrian environment is dangerous & 0.723 & 12.81 \\
\hline \multirow{3}{*}{ IFM } & \multirow{3}{*}{$\begin{array}{l}\text { Inhibition of CC } \\
\text { implementation }\end{array}$} & IFD & CC impedes the freedom to drive & 1.000 & - \\
\hline & & DCU & CC will decrease car use & -0.667 & -7.53 \\
\hline & & IPU & CC will increase public transit use & -0.996 & -11.68 \\
\hline \multirow{4}{*}{ DEC } & \multirow{4}{*}{$\begin{array}{l}\text { Doubts about the } \\
\text { ability of CC policy }\end{array}$} & DCU & CC will decrease car use & 1.000 & - \\
\hline & & RFV & CC effect on reduce frequency of visits to the CBD & 0.385 & 11.03 \\
\hline & & CGW & CC can mitigate congestion and global worming & 0.525 & 12.97 \\
\hline & & IPU & CC will increase public transit use & 0.951 & 11.94 \\
\hline
\end{tabular}

Note: "using ordinal responses of 4-point Likert scale 1 = strongly supported/agreed, 4 = strongly opposed/disaggreed.

Table 3. Description, empirical setting and factor loading for causes (structural equation).

\begin{tabular}{|c|c|c|c|c|c|c|c|}
\hline \multirow{2}{*}{\multicolumn{2}{|c|}{$\begin{array}{c}\text { Variables } \\
\text { Causes }\end{array}$}} & \multicolumn{6}{|c|}{ Path coefficients } \\
\hline & & APR & REC & CDC & APC & IFM & DEC \\
\hline GD & Gender (1 male, 0 otherwise) & 0.065 & - & 0.064 & 0.070 & 0.079 & 0.059 \\
\hline AG & Age ( $1 \geq 40$ years, 0 otherwise) & 0.285 & - & 0.030 & 0.094 & 0.043 & 0.048 \\
\hline $\mathrm{AI}$ & Annual Income (million IDR) & - & 0.014 & 0.274 & 0.160 & - & 0.085 \\
\hline ES & Employment status (1 employed, 0 otherwise) & 0.074 & - & - & - & - & 0.098 \\
\hline
\end{tabular}

Note: all path coefficients have significant at the $5 \%$ level.

implementation as inhibiting their freedom of movement. Interestingly, we found that respondents over 40 years old are more concerned with the appropriateness of CC adoption and have more positive awareness of the problems of cars in society (APC). One possible reason for this is that elderly respondents have relatively greater awareness of the congestion and environmental damage caused by badly autos traffic. This gives them greater expectations for the effect of CC in mitigating congestion and environmental problems. Looking at the variable of annual income, we find that it has a positive correlation with recognition of the effects of CC in mitigating congestion and environmental problems (REC), car dependency (CDC) and awareness of the problems of cars in society (APC). This means that respondents with higher income are more concerned with the problems mani- 
fested by motorization while, on the contrary, path coefficient between annual income (AI) and car dependency (CDC) displays 0.274 . It discloses that they are automobile dependent. This might mean that respondents with higher income live in surrounding municipalities where public transit services are inadequate likely prefer to use private mode. Moreover, as expected, employed respondents are unlikely to endorse the appropriateness of CC adoption in Jakarta. This may be partially because of they need to enter city center more frequently as compared to non-commuter trip makers.

\subsection{Estimation Results of Latent Class}

The observed individual response to CC is treated as an apparent endogenous variable. Respondents were asked to choose a response from a 4-point Likert scale to CC as listed in upper part of Table 4. We combined outcome 3 (not accepted) with outcome 4 to reduce dimension and complexity in estimation procedures. Thus, we set three ordinal outcomes (i.e. 1. well accepted; 2. accepted; 3. combined not accepted) to be apparent endogenous. Description and empirical setting of endogenous and exogenous variables are summarized in Table 4.

Prior to the discussion of the modeling results, we compare the performance of the LC-SORM and LCGORM model specifications. Two goodness and fit measures are conducted to compare performance of two nonnested models. That is, the AIC and Non-Nested Hypothesis (NNH) test. The AIC is defined as $-2 L L+2 K$ and the NNH test can be computed as $\tau=\Phi\left\{-\left[-2\left(\bar{\rho}_{2}^{2}-\bar{\rho}_{1}^{2}\right) L L+\left(K_{2}-K_{1}\right)\right]^{0.5}\right\}$ [21]. Table 5 displays the AIC of LC-SORM and LC-GORM are 2890.72 and 2888.91, respectively and the lower value of AIC is considerably superior. Moreover, the NNH test which compares two non-nested models by computing the probability of $\tau$ based on the $\bar{\rho}^{2}$ obtained in two models. The lower of $\tau$ value (0.001) explicitly indicate that LC-GORM suggests superiority fit over LC-SORM.

Table 4. Empirical and description of endogenous and explanatory variables.

\begin{tabular}{|c|c|c|c|}
\hline Variable & Description & Mean & Std. \\
\hline \multicolumn{4}{|c|}{ Endogenous variable: ordinal preferences of public acceptance to CC reform } \\
\hline \multirow{4}{*}{ ACC } & 1) Well accepted ( $\mathrm{N}=153 ; 9.32 \%)$ & \multirow{4}{*}{2.316} & \multirow{4}{*}{0.693} \\
\hline & 2) Accepted (N = 880; 53.63\%) & & \\
\hline & 3) Not accepted $(\mathrm{N}=545 ; 33.23 \%) \quad$ ] Combined & & \\
\hline & 4) Not accepted at all $(\mathrm{N}=63 ; 3.84 \%) 〕$ Not accepted & & \\
\hline \multicolumn{4}{|c|}{ Exogenous variables } \\
\hline CG & Charge scenarios; numerical (10,000 IDR) & 1.811 & 1.064 \\
\hline APR & Appropriateness of CC adoption; numerical & 0.0477 & 0.105 \\
\hline REC & Recognition effect of CC; numerical & 0.0471 & 0.100 \\
\hline CDC & Car dependency; numerical & 0.0350 & 0.111 \\
\hline $\mathrm{APC}$ & Awareness of problem of cars; numerical & 0.0268 & 0.067 \\
\hline DEC & Doubts about effect of CC; numerical & 0.0442 & 0.068 \\
\hline LD & Dummy; 1 if licensed driver, 0 otherwise & 0.713 & 0.453 \\
\hline PV & Dummy; 1 if used private mode (besides car) $\geq$ 3days/week & 0.239 & 0.427 \\
\hline FV & Frequency of visiting CBDs (days/week) & 2.227 & 1.422 \\
\hline MU & Dummy, 1 used private mode, 0 otherwise & 2.590 & 1.617 \\
\hline FC & Frequency of using car to enter city centers (days/week) & 3.321 & 1.605 \\
\hline $\mathrm{AG}$ & Age, dummy variable with $1 \geq 40$ years, 0 otherwise & 0.135 & 0.342 \\
\hline $\mathrm{PE}$ & Professional employment, dummy 1 if professional, 0 otherwise & 0.697 & 0.460 \\
\hline $\mathrm{TE}$ & Monthly transport expenditure (million IDR) & 0.988 & 0.783 \\
\hline
\end{tabular}


Table 5. Estimation result for LC-SORM and LC-GORM.

\begin{tabular}{|c|c|c|c|c|c|c|}
\hline \multirow{3}{*}{ Variable } & \multicolumn{2}{|c|}{ LC-SORM } & \multicolumn{4}{|c|}{ LC-GORM } \\
\hline & \multirow{2}{*}{ Coefficient } & \multirow{2}{*}{ t-stat } & \multicolumn{2}{|c|}{ Selfish class } & \multicolumn{2}{|c|}{ Altruistic class } \\
\hline & & & Coefficient & t-stat & Coefficient & t-stat \\
\hline \multicolumn{7}{|c|}{ Class-membership selection model: selfish class } \\
\hline Constant & -0.722 & -4.48 & -0.478 & -1.65 & - & - \\
\hline APR & 57.517 & 3.01 & 71.918 & 3.17 & - & - \\
\hline REP & -57.742 & -2.99 & -74.926 & -3.19 & - & - \\
\hline AG & 1.173 & 2.11 & - & - & - & - \\
\hline $\mathrm{PE}$ & -0.204 & -1.82 & -0.208 & -1.45 & - & - \\
\hline $\mathrm{TE}$ & -0.229 & -3.06 & -0.256 & -2.87 & - & - \\
\hline \multicolumn{7}{|c|}{ Class-specific (conditional) choice model 1: selfish class } \\
\hline CG & -0.216 & -2.12 & -0.137 & -1.47 & -0.191 & -2.22 \\
\hline CDC & -16.437 & -4.86 & -9.666 & -2.81 & -8.983 & -2.74 \\
\hline APC & 29.274 & 4.82 & 19.407 & 3.24 & 15.563 & 2.90 \\
\hline DEP & -6.214 & -2.18 & -7.860 & -2.64 & 0.099 & 0.05 \\
\hline LD & -0.755 & -2.80 & -0.396 & -1.61 & -0.479 & -1.64 \\
\hline PV & -0.043 & -0.17 & 0.484 & 1.58 & -0.065 & -0.25 \\
\hline FV & -0.265 & -2.36 & -0.091 & -0.99 & -0.209 & -2.88 \\
\hline MU & -0.272 & -1.61 & -0.209 & -1.34 & -0.072 & -0.48 \\
\hline FC & -0.168 & -2.12 & -0.229 & -3.13 & -0.153 & -1.87 \\
\hline \multicolumn{7}{|c|}{ Class-specific (conditional) choice model 2: altruistic class } \\
\hline CG & -0.089 & -2.39 & 0.082 & 0.36 & -0.067 & -1.61 \\
\hline CDC & -6.640 & -2.97 & - & - & -7.739 & -2.98 \\
\hline APC & 7.179 & 2.26 & - & - & 8.610 & 2.29 \\
\hline DEC & 1.896 & 2.32 & -1.355 & -0.22 & 1.261 & 1.30 \\
\hline LD & -0.229 & -2.45 & -0.890 & -1.82 & -0.214 & -2.09 \\
\hline PV & -0.269 & -2.43 & - & - & -0.306 & -2.52 \\
\hline $\mathrm{FV}$ & -0.119 & -4.10 & -0.246 & -0.90 & -0.108 & -3.26 \\
\hline MU & -0.138 & -2.31 & 0.108 & 0.36 & -0.152 & -2.27 \\
\hline FC & -0.081 & -2.65 & - & - & -0.066 & -1.95 \\
\hline Cut selfish 1 & \multicolumn{2}{|c|}{-1.273} & \multicolumn{2}{|c|}{-1.433} & \multicolumn{2}{|c|}{-} \\
\hline Cut selfish 2 & \multicolumn{2}{|c|}{0.534} & \multicolumn{2}{|c|}{-0.343} & \multicolumn{2}{|c|}{-} \\
\hline Cut altruistic 1 & \multicolumn{2}{|c|}{-6.345} & \multicolumn{2}{|c|}{-} & \multicolumn{2}{|c|}{-0.839} \\
\hline Cut altruistic 2 & \multicolumn{2}{|c|}{-0.625} & & & \multicolumn{2}{|c|}{-0.546} \\
\hline Sample size (n) & \multicolumn{2}{|c|}{1641} & \multicolumn{4}{|c|}{1641} \\
\hline $\mathrm{LL}(0)$ & \multicolumn{2}{|c|}{-1802.82} & \multicolumn{4}{|c|}{-1802.82} \\
\hline $\operatorname{LL}(\beta)$ & \multicolumn{2}{|c|}{-1417.36} & & & & \\
\hline $\bar{\rho}^{2}$ & & & & & & \\
\hline AIC & & & & & & \\
\hline NNH test & & & & & & \\
\hline
\end{tabular}




\subsubsection{Class Membership Selections}

Prior to the discussion the effects of various coefficients on the class-specific (conditional) choice. It is necessary to look after estimation result in the class-membership selections. We used estimated LC-GORM for generating several information as it shown in Table 6. Table 6 displays the likelihood of respondents probabilistically being assigned into selfish and altruistic classes. It reveals that the respondents consigned to class selfish are less (28\%) whereas respondents assigned to altruistic class are predominant $(72 \%)$. Selfish respondents unlikely to prone the CC policy mounting for approximately $42.8 \%$ while altruistic respondents considerably offer significant contribution (48.8\%) being proved well accepted. The results clearly demonstrates that individuals involved in each segments have significant contribution to the scheme's acceptance and the modeling framework by considering latent class reveals that each classes exhibit different choice behavior.

Table 5 (upper part model), estimated parameters correspond to the probability being selected as selfish class. Constant term displays a negative effect. It seems that the more people perceived the sense of injustice (unfair) the more people would not prone the policy is suggesting. Appropriateness of scheme adoption (APR) significantly has a positive contribution to the class selfish. It seems that the more respondents recognize the appropriateness or benefit of such scheme the more people likely would favor CC policy. However, recognition of CC (REP) confirms a negative alert. The likelihoods that insufficient understanding of scheme contributes more appearance of selfish. That is, respondents who lack a clear understanding of the schemes are unlikely to support by selfish class. Looking at personal attributes, the variable of dummy professional employee (PE) and transport expenditure (TE), both variables have a negative effect on determining selfish class. The more person professionally employed there are or the more transport cost be required, the less selfish likely will be.

\subsubsection{Class-Specific (Conditional) Choice Membership}

In the conditional choice models, most of the variables differ much between two classes. Empirically, Table 5 (see middle and lower models) shows that the magnitude of the coefficients (including the t-statistic) vary across outcome categories. These evidences telling us that there are exist an individual preference heterogeneity over ordinal preferences. That is, all significant coefficient parameters in the LC-SORM are not maintain to have same magnitude in the LC-GORM rather randomly distributed over thresholds as it parameterizes to be linear function of the covariates. For instance, the charges (CG) has significant parameter with t-values about -2.12 and -2.39 for selfish and altruistic classes in the LC-SORM, respectively. Whereas in the LC-GORM, CG confirms better fit (t-value -2.22) for selfish, while quite dropped a significant (t-value -1.61) for altruistic within threshold 2. By allowing flexibility of thresholds, it confirms that threshold 2 holds more significant parameters. These evidence discloses that threshold 2 clearly offers superior estimation parameters and carries more meaning concerning respondent's choice behavior compared to threshold 1.

Investigating of charge (CG), parameters show more significant negative sign for selfish class compared to altruistic. It unveils that the more charges are purposing, the more selfish respondent would oppose the scheme. This could tell us that selfish are more sensitive on scheme's rejection compared to altruistic segment. In respecting to latent variables, car dependency (CDC) and problem of awareness (APC) substantially have similar sign and significant parameters for each classes except for altruistic class holding by threshold 1 . It found that less significant for variable doubt the effect of CC (DEC) over class memberships. Investigating of car dependency (CDC) variable, it has a negative sign for each segments. The more they autos dependence the more probably they uses auto to enter the CBD. Part of the reason for this is that, since there is a lack of adequate public transit into the charging zone (with a heavy reliance on Jakarta's BRT), it is likely that people prefer to use their car in terms of its flexibility. Without doubt, auto users tend to oppose proposed policy and are unlikely to reduce use of their cars. However, the variable for awareness of the problem of cars in society (APC) has a positive sign. The likelihood is that respondents are weary of encountering the collective problem of congestion,

Table 6. Segmentations for selfish and altruistic class-memberships based LC-GORM.

\begin{tabular}{|c|c|c|c|c|}
\hline \multirow{2}{*}{ Class memberships } & \multirow{2}{*}{ Probability of respondents' share } & \multicolumn{3}{|c|}{ Probability of acceptance within each segments } \\
\hline & & Well accepted & Accepted & Combined not accepted \\
\hline Selfish & 0.280 & 0.021 & 0.551 & 0.428 \\
\hline Altruistic & 0.720 & 0.488 & 0.285 & 0.227 \\
\hline
\end{tabular}


which is badly manifested in the form of noise and emissions in recent years. They probably look forward to the policy that expected will cut congestion and its externalities.

Concerning to respondent's mobility attributes, it shows that parameters are vary across segments. For instances, selfish class has significant negative parameters for frequency visiting city centers (FV) and frequency used car (FC) while all of them (LD, PV, FV, MU, and FC) have significant negative effect on conditional probability for altruistic class. For both classes, the more frequency visiting CBD (FV) the more likely they are to oppose the scheme. Particularly, this applies to traveler who enter city centers frequently and car users (FC). As for altruistic class, opposition significantly arises from respondents who have driver licensed (LD) and regularly used a private mode (MU) to visit city centers. The presumably that they think that the scheme will limit their freedom of using private vehicles.

\section{Conclusion}

The present study focuses on assessing the effects of various factors on the respondent's choice behavior to a congestion charging proposal in Jakarta. The innovative formulation of the LC-GORM probabilistically assigns respondents into selfish and altruistic class memberships (latently) based on their knowledge on the proposed scheme and respondent's specific attributes. The exogenous attributes, appropriateness and recognition to the scheme, employment status and transportation expenditure are significantly contribute in defining selfish class. Probabilistically, it found that selfish respondents unlikely to prone the CC policy mounting for approximately 42.8\% while altruistic respondents considerably offer significant contribution (48.8\%) being proved well accepted. A comprehensive explanatory variables include charges, latent variables related to respondent's psychological motivations, mobility attributes and socio-demographic characteristics are incorporated into empirical analysis. The finding confirms that altruistic class are more sensitive on scheme's acceptance while selfish are more sensitive on scheme's rejection. The key of factors influencing public's acceptance include charges, car dependency, awareness problem of car society, frequency visiting city centers and frequency used private mode. Empirical findings should provide insight for the government in designing a more acceptable policy in respecting to the charge and public response. Yet, a gradual introduction of scheme outlines to the public may be needed in particular to enhance fairness feeling perceived by public. This may be done by allowing them to gain more understanding the outlines of the scheme, eventually gaining a more acceptable response. We hope this work might help in the design of more effective policy aiming at promoting the adoption of CC in particular for Jakarta and in general for the context of developing countries.

\section{References}

[1] BPS (2010) Statistical Yearbook of Jakarta, Indonesia. Statistics Bureau of the Republic of Indonesia.

[2] JUTPI (2012) Jabodetabek Urban Transportation Policy Integration Project. Ministry of Economic Affairs of the Republic of Indonesia \& Japan International Cooperation Agency, Jakarta.

[3] SITRAMP (2004) The Study on Integrated Transportation Master Plan for Jabodetabek. National Development Planning Agency of the Republic of Indonesia \& Japan International Cooperation Agency, Jakarta.

[4] Janssens, D., Cools, M., Moons, E., Wets, G., Arentze, T.A. and Timmermans, H.J.P. (2009) Road Pricing as an Impetus for Environment-Friendly Travel Behavior: Results from a Stated Adaptation Experiment. Journal of the Transportation Research Record, 115, 50-59.http://dx.doi.org/10.3141/2115-07

[5] Phang, S.Y. and Toh, R.S. (1997) From Manual to Electronic Road Congestion Pricing: the Singapore Experience and Experiment. Transportation Research Part E, 33, 97-106.http://dx.doi.org/10.1016/S1366-5545(97)00006-9

[6] Olszewsi, P. and Xie, L. (2006) Modeling the Effects of Road Pricing on Traffic in Singapore. Transportation Research Part A, 39, 755-772.http://dx.doi.org/10.1016/j.tra.2005.02.015

[7] Eliasson, J. and Mattsson, L.G. (2006) Equity Effects of Congestion Pricing: Quantitative Methodology and a Case Study for Stockholm. Transportation Research Part A, 40, 602-620.http://dx.doi.org/10.1016/j.tra.2005.11.002

[8] May, A.D., Koh, A., Blackledge, D. and Fioretto, M. (2010) Overcoming the Barriers to Implementing Urban Road User Charging Schemes. European Transport Research Review, 2, 53-68. http://dx.doi.org/10.1007/s12544-010-0026-1

[9] Zeng, Z., Liu, Z., Liu, C. and Shiwakoti, N. (2014) Understanding Public Response to a Congestion Charge: A Random-Effects Ordered Logit Approach. Transportation Research Part A, 70, 117-134. http://dx.doi.org/10.1016/j.tra.2014.10.016 
[10] Gaunt, M., Rye, T. and Allen, T. (2007) Public Acceptability of Road Pricing: The Case of Edinburgh and the 2005 Referendum. Transport Reviews, 27, 85-102. http://dx.doi.org/10.1080/01441640600831299

[11] Schaller, B. (2010) New York City's Congestion Pricing Experience and Implications for Road Pricing Acceptance in the United States. The 89th Annual Meeting of the Transportation Research Board, Washington DC, 10-14 January 2010.

[12] Falzarano, S. (2009) Regionwide Congestion Pricing Study in Chicago: Stated Preference Survey Purpose, Approach and Outcomes. The 88th Annual Meeting of the Transportation Research Board, Washington DC, 11-15 January 2009.

[13] Odioso, M. and Smith, M. (2009) Perception of Congestion Charging: Lesson for U.S. Cities from London and Stockholm. The 88th Annual Meeting of the Transportation Research Board, Washington DC, 11-15 January 2009.

[14] Jaensirisak, S., Wardman, M. and May, A.D. (2005) Explaining Variation in Public Acceptability of Road Pricing Scheme. Journal of Transport Economics and Policy, 39, 127-153.

[15] Sugiarto, S., Miwa, T., Sato, H. and Morikawa, T. (2014) Congestion Charging: Influence of Public Consciousness on Acceptability in Jakarta Metropolitan Area (Scientific Paper). Proceedings of 21st World Congress on Intelligent Transport Systems, Detroit, 7-11 September 2014.

[16] Joreskog, K.G. and Goldberger, A.S. (1975) Estimating of a Model with Multiple Indicators and Multiple Causes of a Single Latent Variable. Journal of the American Statistical Association, 70, 631-639. http://dx.doi.org/10.2307/2285946

[17] Long, J.S. (1997) Regression Models for Categorical and Limited Dependent Variables. Sage Publications, Thousand Oaks.

[18] Winkelmann, R. and Boes, S. (2009) Analysis of Microdata. 2nd Edition, Springer, Berlin.

[19] Maddala, G.S. (1983) Limited Dependent and Qualitative Variables in Econometrics. Cambridge University Press, Cambridge. http://dx.doi.org/10.1017/CBO9780511810176

[20] Hooper, D., Coughlan, J. and Mullen, M.R. (2008) Structural Equation Modelling: Guidelines for Determining Model Fit. Electronic Journal of Business Research Methods, 6, 53-60.

[21] Ben-Akiva, M. and Lerman, S.R. (1985) Discrete Choice Analysis: Theory and Application to Travel Demand. The MIT Press, Cambridge. 